\title{
Toxicités sévères des immunothérapies du cancer
}

\author{
Severe Toxicities Associated with Cancer Immunotherapy
}

\author{
L. Campedel $\cdot$ S. Assoun $\cdot$ S. Bécourt $\cdot$ O. Nguyen $\cdot$ F. Ledoux $\cdot$ L. Doucet $\cdot$ M. Espié $\cdot$ L. Teixeira \\ Reçu le 16 mai 2018; accepté le 15 octobre 2018 \\ (C) SRLF et Lavoisier SAS 2018
}

Résumé L'immunothérapie représente une avancée récente et importante en cancérologie. Les inhibiteurs de checkpoints immunitaires, ciblant les protéines PD-1, PD-L1 et CTLA-4, sont les thérapies les plus prometteuses et sont utilisés dans la prise en charge de plusieurs cancers. Les toxicités associées à ces traitements sont généralement moins fréquentes et moins graves que celles associées aux chimiothérapies et à la plupart des thérapies ciblées. Cependant, il existe un certain nombre de toxicités spécifiques de ce type de traitement, qui peuvent parfois être sévères et dont les plus fréquentes sont les toxicités pulmonaire, digestive, endocrinienne et cutanée. Dans cette mise au point, nous reviendrons sur la fréquence, le mécanisme et les principes de traitement des différentes toxicités sévères associées à l'immunothérapie.

Mots clés Immunothérapie · Toxicités sévères · PD-1 · PD-L1 · CTLA-4

\begin{abstract}
Immunotherapy represents a recent and important advance in oncology. The immune checkpoint inhibitors, targeting the PD-1, PD-L1 and CTLA-4 proteins, are the most promising therapies and are used in the management of several cancers. The toxicities associated with these treatments are generally less frequent and less severe than those asso-
\end{abstract}

L. Campedel $(\bowtie) \cdot$ S. Bécourt · O. Nguyen · F. Ledoux ·

M. Espié · L. Teixeira

Sénopôle Territoire Cancer Nord, hôpital Saint-Louis,

1, avenue Claude-Vellefaux, F-75475 Paris cedex 10, France

e-mail : luca.campedel@gmail.com

L. Campedel $\cdot$ S. Assoun

Sorbonne Université, F-75005 Paris, France

O. Nguyen · F. Ledoux $\cdot$ M. Espié $\cdot$ L. Teixeira Inserm/CNRS UMR944/7212, université Paris-Diderot, Sorbonne Paris-Cité, F-75013 Paris, France

L. Doucet $\cdot$ L. Teixeira

Service d'oncologie médicale, hôpital Saint-Louis,

1, avenue Claude-Vellefaux, F-75475 Paris cedex 10, France ciated with chemotherapy and most targeted therapies. However, there are a number of toxicities that are specific to this type of treatment, which can sometimes be severe and the most frequent are pulmonary, digestive, endocrine and cutaneous toxicities. In this article, we will discuss the frequency, mechanism and principles of treatment of the different severe toxicities associated with immunotherapy.

Keywords Immunotherapy - Severe toxicities · PD-1 · PD-L1 · CTLA-4

\section{L'immunologie, entrée tardive dans les caractéristiques du cancer}

En 2000, Hanahan et Weinberg ont énoncé six caractéristiques fondamentales acquises, toutes ou en partie, par la cellule cancéreuse au cours de son développement : induction de l'angiogenèse, potentiel réplicatif illimité, capacité de donner des métastases à distance, autosuffisance en signaux de croissance, insensibilité aux signaux inhibiteurs de croissance et capacité à éviter l'apoptose [1]. Ces caractéristiques sont autant de cibles thérapeutiques qui ont permis l'émergence de nombreux traitements dirigés contre chacune d'entre elles tels que les anti-VEGF (vascular endothelial growth factor), les anti-EGFR (epidermal growth factor receptor), les proapoptotiques ou les inhibiteurs de cyclines-dépendantes-kinases par exemple. En 2011, ces deux auteurs ont mis à jour leur publication en rajoutant un certain nombre d'autres caractéristiques parmi lesquelles la capacité à éviter la destruction par le système immunitaire [2] ; c'est la reconnaissance de l'immunité comme cible thérapeutique potentielle.

\section{Histoire et efficacité de l'immunothérapie}

L'immunothérapie connait depuis une quinzaine d'années un essor important et est actuellement considérée comme la principale thérapie d'avenir. On admet communément que 
la naissance de l'immunothérapie est due à Coley et ses injections de streptocoques dans les tumeurs en 1893 (permettant notamment la découverte du tumor necrosis factor [TNF]) [3]. Elle a depuis suscité de nombreuses désillusions, mais aussi quelques réussites telles que le traitement par instillations de bacille de Calmette et Guérin (BCG) dans les tumeurs de vessie, qui reste encore un standard pour les tumeurs de vessie n'envahissant pas le muscle (TVNIM) de risque intermédiaire ou haut [4], les greffes de moelle, via les cellules souches hématopoïétiques $(\mathrm{CSH})$ ou le sang du cordon dans le cadre des allogreffes depuis 1957, qui est également un standard pour un certain nombre de pathologies lymphoïdes ou myéloïdes (en particulier les leucémies aiguës myéloïdes et lymphoïdes), ainsi que l'interleukine-2 (IL-2) et l'interféron-alpha (IFN-alpha) dans les cancers du rein et les mélanomes [5]. Mais la vraie révolution s'est opérée il y a 15 ans avec l'émergence de l'immunothérapie comme pilier essentiel du traitement des cancers, en particulier, via la découverte des inhibiteurs de checkpoints immunitaires, qui sont des thérapies permettant de lever la tolérance immunitaire exercée par la tumeur, les anti-CTLA-4 et les anti-PD-1 (programmed cell death-1)/PD-L1 (programmed cell death ligand-1) étant les principales thérapies de ce type développées. Les principaux autres axes de développement dans ce domaine sont représentés par la recherche sur les CAR T-cells (chimeric antigen receptor t-cells), technologie qui consiste à purifier les lymphocytes $\mathrm{T}$ du sang périphérique des patients et à y introduire un récepteur reconnaissant un antigène tumoral, avec des résultats significatifs dans les leucémies [6], et les vaccinations, plutôt décevantes jusqu'à maintenant hormis dans le cancer de prostate [7]. De nombreux travaux ont par ailleurs montré que même les thérapies conventionnelles comme la chimiothérapie (concept de mort immunogénique induite par les chimiothérapies), la radiothérapie, et les anticorps non dirigés contre des voies de l'immunité, étaient capables d'activer le système immunitaire [8], ce qui fait véritablement de ce dernier un acteur et un partenaire majeur de la prise en charge en cancérologie.

\section{Inhibiteurs de « checkpoint » : PD-1/PD-L1 et CTLA-4 (Fig. 1)}

Un des mécanismes fondamentaux de la réaction immunitaire est la présentation d'antigènes aux lymphocytes $T$, par des cellules spécialisées dites cellules présentatrices d'antigènes (CPA). Les CPA comprennent trois familles cellulaires : les macrophages (présents dans les tissus lymphoïdes, les tissus conjonctifs), les cellules dendritiques (présentes dans les épithéliums, dont la peau, les tissus conjonctifs et les tissus lymphoïdes) et les cellules B (sang et tissus lymphoïdes). À la surface des CPA se trouve le complexe majeur d'histocompatibilité (CMH), un groupe de molécules qui se combine à l'antigène pour le présenter au lymphocyte. On trouve également à la surface des CPA une molécule spécifique, le B7, qui sert de corécepteur. Le lymphocyte entre en contact avec la CPA par deux récepteurs : un récepteur direct, le TCR (T-Cell Receptor) qui se lie au complexe $\mathrm{CMH}$-antigène et un corécepteur, le $\mathrm{CD} 28$, qui se lie avec le $\mathrm{B} 7$ présent à la surface de la CPA. La molécule B7 joue également un rôle important dans l'activation du lymphocyte, qui, par suite, sera capable de détruire les cellules porteuses de l'antigène présenté par la CPA : par exemple, des cellules infectées par un virus ou des cellules cancéreuses. Le CTLA-4 est une molécule normalement exprimée à la surface de la cellule $\mathrm{T}$ qui joue un rôle antagoniste de celui du CD28 : il entre en compétition avec le CD28 dans sa liaison avec la molécule B7 de la CPA, et lorsqu'il se lie, réduit l'activation de la cellule $\mathrm{T}$ et stimule la sécrétion par la CPA de facteurs inhibiteurs de la cellule T. L'interaction complexe entre les différents facteurs, certains étant activateurs, d'autres inhibiteurs de la cellule $\mathrm{T}$, permet une régulation de la réponse immunitaire et l'évitement de réactions excessives d'auto-immunité à l'état physiologique. Certaines cellules cancéreuses expriment la molécule CTLA-4, ce qui leur permet de réduire l'activation des cellules $\mathrm{T}$ [9]. La protéine PD-1 (programmed cell death protein-1), immunoglobuline présente à la surface des lymphocytes $\mathrm{T}$, des lymphocytes $\mathrm{B}$ et des macrophages, a un rôle de régulation négative de la réponse immunitaire, parmi d'autres multiples costimulateurs et inhibiteurs qui régulent l'activité des lymphocytes T [10]. Les ligands de PD-1, PD-L1 et PD-L2, lorsqu'ils sont exprimés par les cellules tumorales, exercent un effet inhibiteur sur les lymphocytes $\mathrm{T}$, permettant ainsi l'échappement tumoral. Le blocage de CTLA-4, PD-L1 ou PD-1 permet de restaurer la réponse immune antitumorale. Des médicaments agissant sur ces cibles ont été développés ou sont en cours de développement. Pour les anti-CTLA-4, les deux médicaments actuellement disponibles sont l'ipilimumab et le trémélimumab ; pour les anti-PD-1, actuellement disponibles ou à l'étude, nivolumab, pembrolizumab et pidilizumab ; pour les anti-PD-L1, actuellement disponibles ou à l'étude, atézolizumab, durvalumab, avélumab et MDX-1105. Les AMM françaises disponibles pour ces médicaments sont résumées dans le tableau 1.

\section{Rationnel et indications}

\section{Immunogénicité différentielle en fonction des tumeurs}

\section{Charge mutationnelle}

Il est possible de classer les tumeurs en fonction de leur taux de mutations somatiques, à différencier des mutations 
A
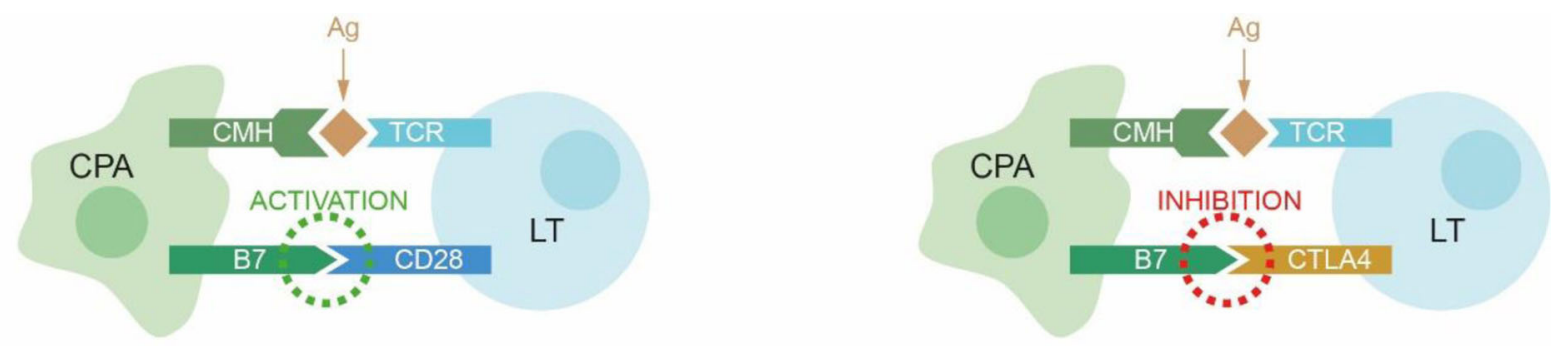

B

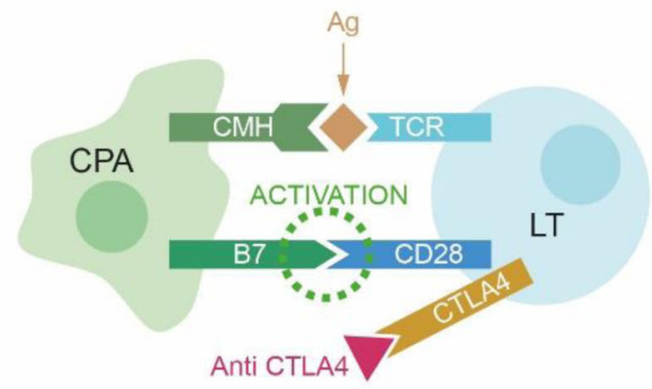

C

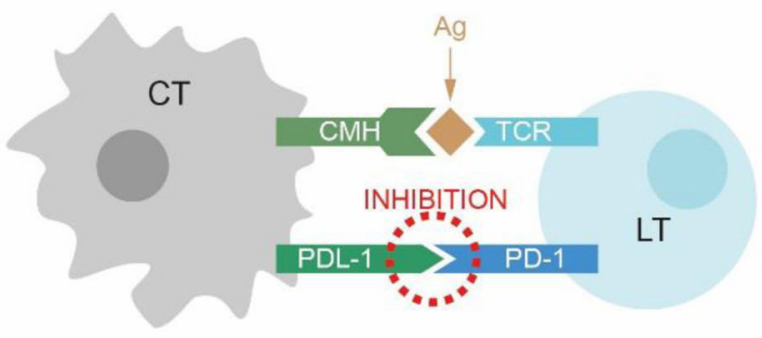

D

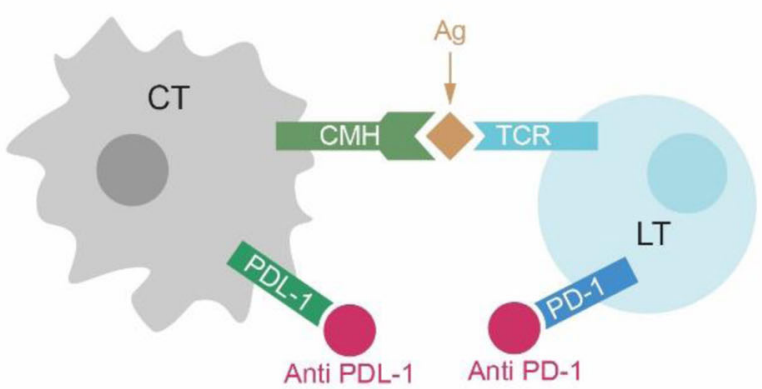

Fig. 1 Interaction des cellules $\mathrm{T}$ avec les cellules dendritiques et les cellules tumorales : les points de contrôle immunitaires CTLA-4 et PD-1/PD-L1. A. À l'état physiologique, après présentation de l'antigène par le CMH du CPA au récepteur du lymphocyte T, il y a activation parallèle du corécepteur activateur CD28 par le B7 du lymphocyte T qui amplifie l'activation lymphocytaire. Le CTLA-4, corécepteur inhibiteur, va entrer en compétition avec le CD28 dans sa liaison au B7 afin de réguler la réponse immunitaire. B. L'utilisation d'anti-CTLA-4 permet d'inhiber le signal inhibiteur et donc d'activer la réponse immunitaire. C. À l'état physiologique, la protéine PDL1 exprimée par les CPA va se fixer sur le récepteur PD-1 des lymphocytes $\mathrm{T}$ afin de réguler négativement la réponse immunitaire et d'éviter ainsi une activation excessive. La cellule tumorale est capable d'exprimer PD-L1 et d'ainsi inhiber la réponse immunitaire et permettre la progression tumorale. D. L'utilisation d'anticorps anti-PD-1 ou anti-PD-L1 va permettre de restaurer la réponse immunitaire 
Tableau 1 Indications de l'immunothérapie (anti-CTLA-4/anti-PD-1/anti-PD-L1) dans les tumeurs solides au $1^{\mathrm{er}}$ avril 2018

\begin{tabular}{|c|c|c|c|c|c|}
\hline Molécule & Mélanome & $\begin{array}{l}\text { Cancer } \\
\text { du rein }\end{array}$ & $\begin{array}{l}\text { Cancer du poumon non } \\
\text { à petites cellules }\end{array}$ & Cancer de vessie & Autres \\
\hline \multicolumn{6}{|l|}{ Anti-CTLA-4 } \\
\hline $\begin{array}{l}\text { Ipilimumab } \\
\text { (Yervoy, BMS) }\end{array}$ & $\begin{array}{l}\text { Avancé : } \\
\cdot 1^{\text {re }} \text { ligne } \\
\text { en association } \\
\text { au nivolumab } \\
\cdot \geq 2^{\text {e }} \text { ligne si } \\
\text { absence } \\
\text { de mutation } \\
\text { BRAF V600 } \\
\bullet \geq 3^{\text {e ligne si }} \\
\text { BRAF muté }\end{array}$ & & & & \\
\hline $\begin{array}{l}\text { Trémélimumab } \\
\text { (AstraZeneca) }\end{array}$ & \multicolumn{5}{|c|}{ Pas d'AMM } \\
\hline \multicolumn{6}{|l|}{ Anti-PD-1 } \\
\hline $\begin{array}{l}\text { Nivolumab } \\
\text { (Opdivo, BMS) }\end{array}$ & $\begin{array}{l}\text { Avancé : } \\
\text { - } 1^{\text {re }} \text { ligne } \\
\text { en monothérapie } \\
\text { ou en association } \\
\text { à l'ipilimumab }\end{array}$ & $\begin{array}{l}\text { Avancé : } \\
\geq 2^{\mathrm{e}} \text { ligne }\end{array}$ & $\begin{array}{l}\text { Avancé : } \\
\geq 2^{\mathrm{e}} \text { ligne après } \\
\text { chimiothérapie }\end{array}$ & & $\begin{array}{l}\text { - Lymphome } \\
\text { de Hodgkin en rechute/ } \\
\text { réfractaire après } \\
\text { autogreffe de cellules } \\
\text { souches } \\
\text { hématopoïétiques } \\
(\mathrm{CSH}) \text { et après } \\
\text { brentuximab vedotin } \\
\text { (anti-CD30) } \\
\text { - Carcinome } \\
\text { épidermoïde de la tête } \\
\text { et du cou en progression } \\
\text { pendant ou après } \\
\text { une chimiothérapie } \\
\text { à base de sels de platine }\end{array}$ \\
\hline $\begin{array}{l}\text { Pembrolizumab } \\
\text { (Keytruda, } \\
\text { Merck) }\end{array}$ & $\begin{array}{l}\text { Avancé : } \\
\text { - } 1^{\text {re }} \text { ligne } \\
\text { en monothérapie }\end{array}$ & & $\begin{array}{l}\text { Avancé : } \\
\cdot 1^{\text {re }} \text { ligne si expression } \\
\text { de PD-L1 } \\
\text { dans les cellules } \\
\text { tumorales } \geq 50 \% \text {, sans } \\
\text { mutations d'EGFR } \\
\text { ou d'ALK } \\
\cdot \geq 2^{\mathrm{e}} \text { ligne si expression } \\
\text { de PD-L1 } \\
\text { dans les cellules } \\
\text { tumorales } \geq 1 \% \text { (si } \\
\text { mutation EGFR ou ALK, } \\
\text { les patients doivent } \\
\text { également avoir reçu } \\
\text { un traitement autorisé } \\
\text { dans cette indication) }\end{array}$ & $\begin{array}{l}\text { Avancé : } \\
\cdot 1^{\text {re }} \text { ligne } \\
\text { chez les patients } \\
\text { inéligibles } \\
\text { à une chimiothérapie } \\
\text { à base de cisplatine } \\
\bullet \geq 2^{\mathrm{e}} \text { ligne après échec } \\
\text { d'une chimiothérapie } \\
\text { par sels de platine }\end{array}$ & $\begin{array}{l}\text { Lymphome de Hodgkin } \\
\text { en rechute/réfractaire } \\
\text { après autogreffe } \\
\text { de CSH et après } \\
\text { brentuximab vedotin } \\
\text { (anti-CD30) }\end{array}$ \\
\hline
\end{tabular}




\begin{tabular}{|c|c|c|c|c|c|}
\hline Molécule & Mélanome & $\begin{array}{l}\text { Cancer } \\
\text { du rein }\end{array}$ & $\begin{array}{l}\text { Cancer du poumon non } \\
\text { à petites cellules }\end{array}$ & Cancer de vessie & Autres \\
\hline \multicolumn{6}{|l|}{ Anti-PD-L1 } \\
\hline $\begin{array}{l}\text { Atézolizumab } \\
\text { (Tecentriq, } \\
\text { Roche) }\end{array}$ & & & $\begin{array}{l}\text { Avancé : } \\
\geq 2^{\mathrm{e}} \text { ligne (si mutation } \\
\text { EGFR ou ALK, } \\
\text { les patients doivent } \\
\text { également avoir reçu } \\
\text { un traitement autorisé } \\
\text { dans cette indication) }\end{array}$ & $\begin{array}{l}\text { Avancé : } \\
\cdot 1^{\text {re }} \text { ligne } \\
\text { chez les patients } \\
\text { inéligibles } \\
\text { à une chimiothérapie } \\
\text { à base de cisplatine } \\
\cdot \geq 2^{\text {e }} \text { ligne après échec } \\
\text { d'une chimiothérapie } \\
\text { par sels de platine }\end{array}$ & \\
\hline $\begin{array}{l}\text { Durvalumab } \\
\text { (Imfinzi, } \\
\text { AstraZeneca } \\
\text { Canada, Inc.) }\end{array}$ & \multicolumn{5}{|c|}{ Pas d'AMM } \\
\hline $\begin{array}{l}\text { Avélumab } \\
\text { (Bavencio, } \\
\text { Merck) }\end{array}$ & & & & & $\begin{array}{l}\text { Carcinome à cellules } \\
\text { de Merkel }(\mathrm{CCM}) \\
\text { métastatique, dont } \\
\text { la maladie a progressé } \\
\text { après avoir reçu } \\
\text { au moins une ligne } \\
\text { de chimiothérapie } \\
\text { antérieure }\end{array}$ \\
\hline
\end{tabular}

germinales qui entrent dans le cadre d'un certain nombre de maladies génétiques. Ainsi, Alexandrov et al. ont analysé 4938362 mutations provenant de 7042 cancers, extrait plus de 20 signatures mutationnelles distinctes [11] et démontré la grande disparité dans le taux de mutations somatiques entre les différents types de cancers. Les taux de mutations les plus élevés sont retrouvés pour le mélanome, le cancer du poumon (que ce soit le carcinome épidermoïde ou l'adénocarcinome) et le carcinome urothélial de vessie, observations confirmées par Lawrence et al. sur 3083 tumeurs [12]; or, ce sont ces types tumoraux qui répondent particulièrement à l'immunothérapie. Une corrélation a même été rapportée entre la charge mutationnelle tumorale (évaluée par séquençage haut débit) et la réponse aux anticorps anti-PD-1/PD-L1 et anti-CTLA-4 pour des patients présentant un même type tumoral dans le cancer du côlon, le mélanome et le cancer du poumon à petites cellules et non à petites cellules [13-18]. Ces constatations démontrent bien le lien entre charge mutationnelle et efficacité de l'immunothérapie.

\section{Importance du microenvironnement}

Les tumeurs solides humaines présentent une infiltration par des cellules immunitaires polymorphes en densité variable. Cet infiltrat est composé de cellules de l'immunité innée (macrophages, cellules dendritiques immatures, polynucléaires, cellules NK, NK-T, T $\gamma \delta$, ILCs) et de cellules de l'immunité adaptative présentant un récepteur à l'antigène ; les lymphocytes B et T. Il a été montré pour plusieurs tumeurs solides sensibles aux thérapies ciblant les inhibiteurs de checkpoints immunitaires, telles que les mélanomes, les cancers de la vessie, du poumon, du rein et du côlon, qu'une forte infiltration LT CD3, T CD8 cytotoxique et T CD45RO mémoire intratumorale était associée à un gain de survie sans récidive (DFS) et/ou de survie globale (OS) $[19,20]$. Les données issues des premiers essais d'immunothérapie avec des anti-CTLA-4 dans le mélanome ont confirmé cette hypothèse ; la densité des lymphocytes $\mathrm{T}$ infiltrant la tumeur (TIL) et le niveau d'expression de gènes impliqués dans la réponse immunitaire d'orientation Th1 cytotoxique étaient des marqueurs prédictifs de réponse $[16,21,22]$.

\section{Autres biomarqueurs}

Des biomarqueurs circulants peuvent être utilisés pour prédire la réponse à l'immunothérapie, le plus connu étant le rapport neutrophiles/lymphocytes, dont le taux élevé est prédictif de mauvaise réponse dans différents types de cancers tels que le CBNPC [23] ou le mélanome [24]. Le score LIPI 
(Lung Immune Prognostic Index), qui combine le rapport neutrophiles/lymphocytes et la protéine $\mathrm{C}$ réactive (CRP), a montré dans le CBNPC un impact pronostique pour la réponse aux inhibiteurs de checkpoints immunitaires [25]. À ce jour, aucun de ces biomarqueurs circulants n'est utilisé pour cibler les patients répondeurs aux traitements. L'expression des protéines PD-1 et PD-L1 comme marqueur prédictif de réponse à l'immunothérapie a par ailleurs été largement étudiée. En effet, il est possible de classer les tumeurs en fonction de l'expression de PD-1 et de PD-L1 en immunohistochimie et d'ainsi construire des groupes d'expression à l'intérieur d'un type tumoral. Cependant, les résultats sont très hétérogènes, voire parfois discordants, et la valeur prédictive de ce marquage est encore discutée. Cela peut être expliqué par l'hétérogénéité de l'expression de PD-L1 dans la tumeur, les différents kits d'anticorps utilisés dont la concordance est remise en cause ou la reproductibilité entre anatomopathologistes. Un seul traitement possède actuellement en France une AMM conditionnée par l'expression de PD-L1, le pembrolizumab (anti-PD-1) dans le CBNPC (en première ligne métastatique si expression de PD-L1 dans les cellules tumorales supérieure à $50 \%$, et en deuxième ligne métastatique si expression supérieure à $1 \%$ ) (Tableau 1).

\section{Particularité de l'immunothérapie : pseudoprogression et hyperprogression}

\section{Pseudoprogression}

La pseudoprogression se caractérise par une progression tumorale initiale, suivie d'une réponse secondaire, sans modification du traitement. Elle est une quasi-particularité des tumeurs sous immunothérapie, mais peut se produire aussi lors du traitement des glioblastomes par exemple, en particulier après radiothérapie ou anti-VEGF et dans les hépatocarcinomes ou les métastases hépatiques de tumeurs solides lors du traitement par anti-VEGF, mais correspond dans ces cas à une nécrose tumorale faussement assimilée à une progression par l'imagerie. Dans le cas de l'immunothérapie, pour laquelle la pseudoprogression correspond à un infiltrat lymphocytaire [26], une nouvelle échelle a été développée en supplément des critères OMS (Organisation mondiale de la santé) ou RECIST (Response Evaluation Criteria in Solid Tumors), la classification iRECIST qui prend en compte la possibilité d'une progression transitoire de type «pseudoprogression » [27]. Cette échelle est encore à l'étude, utilisée dans le cadre d'essais cliniques et ne doit pas remplacer en pratique la classification RECIST 1.1 [27]. L'origine de cette nouvelle classification vient du fait qu'il a été montré que plusieurs cas de figure, autres qu'une diminution du volume tumoral, étaient associés à une augmentation de la survie sous immunothérapie : une stabilité tumorale, une réponse après une augmen- tation initiale du volume tumoral et une réponse tumorale avec apparition de nouvelles lésions [28]. Si la possibilité d'une pseudoprogression doit être prise en compte au moment de la décision d'admission en réanimation d'un patient en progression tumorale, il ne faut cependant pas surestimer ce phénomène, celui-ci restant extrêmement rare et se produisant surtout lors du traitement des mélanomes (jusqu'à $10 \%$ des cas) plutôt que dans les autres tumeurs solides (moins de $2 \%$ des cas) [29]. Récemment, Kurra et al. ont montré sur une cohorte de 356 patients extraite des essais cliniques de phases I et II menés avec les inhibiteurs de checkpoints immunitaires entre 2008 et 2015 et comprenant majoritairement des mélanomes, des cancers bronchiques et des cancers du sein, que la pseudoprogression était un événement rare $(2 \%$ avec RECIST, $6 \%$ avec iRECIST) mais corrélé positivement avec la survie à un an $(100 \%$ des cas avec RECIST, soit un taux supérieur à celui des patients en réponse partielle initiale, $81 \%$ avec iRECIST) [30]. De plus, dans cette même étude, les auteurs montraient que la réponse secondaire pouvait se produire jusqu'à un an après initiation du traitement [30].

\section{Hyperprogression}

Il existe des cancers qui sont considérés comme « hyperprogresseurs ", c'est-à-dire que les lésions tumorales vont évoluer rapidement sous immunothérapie. Afin de ne pas méconnaître ce phénomène qui peut conduire à une évolution rapidement péjorative, une évaluation précoce par scanner thoraco-abdomino-pelvien (TAP) à quatre semaines du début du traitement d'immunothérapie est le plus souvent réalisée. En cas de progression rapide et importante, une deuxième ligne de traitement est rapidement initiée. En cas de progression modérée à quatre semaines, c'est la clinique qui permettra de trancher entre poursuite du traitement dans l'hypothèse d'une pseudoprogression en cas de stabilité ou d'amélioration clinique et changement de ligne de traitement en cas d'aggravation clinique.

Du fait du mode évolutif particulier des lésions tumorales sous immunothérapie, une concertation entre réanimateur et oncologue est indispensable pour évaluer le pronostic et décider de l'intensité de soins lors de la prise en charge de ces patients, et pour ne pas méconnaître une pseudoprogression, ou à l'inverse une hyperprogression, qui modifie complètement la prise en charge.

\section{Différents types de toxicités}

Bien que ce nouveau pilier de la prise en charge du cancer montre des résultats exceptionnels et soit le plus souvent mieux toléré que la chimiothérapie, il n'en demeure pas moins qu'il présente un certain nombre de toxicités plus ou moins spécifiques et parfois graves. La réactivation 
immunitaire engendrée par les inhibiteurs de checkpoints immunitaires, qui concerne à la fois les lymphocytes $\mathrm{T}$, les lymphocytes B via la sécrétion d'anticorps, les cellules de l'immunité innée et les cytokines, peut provoquer une atteinte de chaque organe, en anglais irAE (immune related Adverse Events) [31]. L'objectif du traitement de ces toxicités est de bloquer la réaction inflammatoire sans influer sur la réaction immunitaire antitumorale, via par exemple les corticoïdes, les antihistaminiques et les anti-TNF de manière transitoire. Nous développerons les toxicités provoquées par les thérapies les plus prometteuses actuellement, les antiPD-1/PD-L1 et les anti-CTLA-4, ainsi que leurs traitements respectifs. Généralement, les toxicités graves sont moins fréquentes avec les anti-PD-1/PD-L1 qu'avec les anti-CTLA-4 avec respectivement 7 à $12 \%$ contre 10 à $18 \%$ de toxicités de grade 3/4 dans les études de phase III [32]. Dans la plupart des cas, ces toxicités mêmes graves sont réversibles et ne doivent de fait en aucun cas contre-indiquer la prise en charge en réanimation.

\section{Pulmonaire}

L'incidence des pneumopathies interstitielles diffuses est d'environ 3-5\% tous grades de toxicité confondus et de $1 \%$ de grade 3 ou plus (Tableau 2), et ne semble pas différente qu'il s'agisse des anti-PD1 ou des anti-PD-L1, ou de la ligne de traitement à laquelle est donnée l'immunothérapie [33-36]. Le délai d'apparition médian dans la principale étude menée par le MSKCC (Memorial Sloan Kettering Cancer Center) évaluant les pneumopathies sous antiPD-1/PD-L1 seuls ou en association à un anti-CTLA-4 était de 2,8 mois avec de larges bornes ( 9 jours à 19,2 mois) et une tendance à être plus précoce et plus fréquente lorsque l'immunothérapie était donnée en combinaison, mais sans augmentation de la gravité de l'atteinte [33]. Des chiffres relativement identiques étaient retrouvés dans le travail du Dana Farber Institute reprenant les pneumopathies immuno-induites des patients traités par nivolumab avec un délai médian de 2,6 mois $(0,5-11,5)$ ou dans la série française de Delaunay et al. avec 2,3 mois $(0,2-27,4)$ [37].

Les symptômes décrits sont souvent peu spécifiques, dyspnée, toux ou douleur thoracique, et l'atteinte peut même être asymptomatique (un tiers des cas). Dans plus d'un cas sur deux, la toxicité pulmonaire est associée à une autre toxicité immuno-induite [33]. Il n'existe pas d'atteinte radiologique pathognomonique ; elle peut prendre, par ordre de fréquence, la forme de «pneumopathie organisée » $(\mathrm{PO})$, de pneumopathie interstitielle non spécifique (PINS), de pneumopathie d'hypersensibilité (PHS) ou alors de syndrome de détresse respiratoire aiguë (SDRA) [33,37,38]. Devant l'absence de critères pathognomoniques, le diagnostic de pneumopathie interstitielle aux anti-PD-1/PD-L1 est un diagnostic d'élimination après exploration complète éliminant une autre cause, en particulier une dysfonction ventriculaire gauche, une progression tumorale ou une cause infectieuse. La fibroscopie bronchique avec lavage bronchoalvéolaire permet d'éliminer une infection ou une progression tumorale et peut apporter des arguments en faveur d'une toxicité pulmonaire de l'immunothérapie (alvéolite lymphocytaire, infiltrat lymphocytaire si biopsie bronchique). Selon les recommandations de l'ESMO ([European Society of Medical Oncology] ou Société européenne d'oncologie médicale), une biopsie pulmonaire chirurgicale vidéoassistée peut être pratiquée pour confirmer le diagnostic [39].

Dans la série du MSKCC, comprenant 43 cas (en majorité des mélanomes ou des cancers bronchiques non à petites cellules) avec ou sans association à un anti-CTLA-4, une grande majorité des pneumopathies $(88 \%, 37 / 43)$ étaient améliorées/réversibles après arrêt du médicament et/ou corticothérapie, et un décès était attribuable directement à la pneumopathie ; $27 \%$ des atteintes étaient de grades 3, 4 ou 5 (Tableau 2) et parmi celles-là, $64 \%(7 / 12)$ étaient améliorées ou réversibles sous traitement [33]. Dans le travail du Dana Farber Institute regroupant 20 cas (mélanomes, lymphomes, cancers bronchiques), $25 \%$ des toxicités étaient de grades 3 et 4 avec notamment deux patients ayant nécessité un transfert en réanimation, dont une intubation [38]. Dans $90 \%$ des cas $(18 / 20)$ s'ensuivait une amélioration clinicoradiologique (17 des 18 patients ayant reçu une corticothérapie) [38]. Dans la phase I du nivolumab, trois décès liés à une atteinte respiratoire non infectieuse ont été observés (deux patients avec un cancer bronchique non à petites cellules et un patient avec un cancer colorectal) [40]; plus récemment, Nishino et al. ont rapporté deux cas de SDRA avec transfert en réanimation, l'un chez un patient traité par nivolumab et ipilimumab de manière séquentielle ayant conduit au décès et l'autre chez un patient avec nivolumab en monothérapie [41]. Parmi les patients dont l'atteinte a été complètement réversible, une récidive de l'atteinte pulmonaire à la réintroduction du médicament était retrouvée dans moins d'un tiers des cas (3 cas sur 12 [25\%] dans la série de Naidoo et al. [33], deux cas sur sept [29\%] dans la série de Nishino et al. [38]). Dans la série française de Delaunay et al. sur les cas de pneumopathies interstitielles recueillis, $9,4 \%$ ont conduit au décès [37].

Le traitement comporte au grade 1 l'arrêt possiblement temporaire du médicament, à partir du grade 2 l'association à une corticothérapie, aux grades 3 et 4 (Tableau 2) une prise en charge spécialisée d'organe en plus de ces deux mesures. La poursuite de la corticothérapie doit se faire plus de six semaines après la résolution ou l'amélioration des symptômes et par une décroissance très progressive afin d'éviter une récidive. Dans les cas les plus sévères, il est possible de réaliser des bolus de corticoïdes. En cas de persistance des symptômes malgré la corticothérapie, les recommandations de l'ESMO proposent au bout de 48 heures de discuter 
Tableau 2 Grades de sévérité des principales toxicités liées aux inhibiteurs de « checkpoints » immunitaires selon le CTCAE (Common Terminology Criteria for Adverse Event) v 5.0

\begin{tabular}{|c|c|c|c|c|c|}
\hline Type de toxicité & Grade 1 & Grade 2 & Grade 3 & Grade 4 & Grade 5 \\
\hline Colite & $\begin{array}{l}\text { Asymptomatique ; } \\
\text { diagnostic à l'examen } \\
\text { clinique } \\
\text { ou à l'imagerie } \\
\text { uniquement ; } \\
\text { ne nécessitant aucun } \\
\text { traitement }\end{array}$ & $\begin{array}{l}\text { Douleurs } \\
\text { abdominales ; } \\
\text { présence de mucus } \\
\text { ou de sang } \\
\text { dans les selles }\end{array}$ & $\begin{array}{l}\text { Douleurs abdominales } \\
\text { sévères ; modification } \\
\text { des habitudes } \\
\text { de défécation ; } \\
\text { nécessitant } \\
\text { un traitement } \\
\text { médical ; signes } \\
\text { péritonéaux }\end{array}$ & $\begin{array}{l}\text { Mise en jeu } \\
\text { du pronostic vital ; } \\
\text { nécessitant une prise } \\
\text { en charge en urgence }\end{array}$ & Décès \\
\hline Cytolyse hépatique & $\mathrm{N}<\mathrm{X}<3 \mathrm{~N}$ & $3 \mathrm{~N}<\mathrm{X}<5 \mathrm{~N}$ & $5 \mathrm{~N}<\mathrm{X}<20 \mathrm{~N}$ & $>20 \mathrm{~N}$ & - \\
\hline Diarrhées & $\begin{array}{l}\text { Augmentation de } 4 \text { ou } \\
\text { moins du nombre } \\
\text { de selles par jour } \\
\text { par rapport à l'état } \\
\text { initial ; légère } \\
\text { augmentation } \\
\text { des volumes de stomie } \\
\text { par rapport à l'état } \\
\text { initial }\end{array}$ & $\begin{array}{l}\text { Augmentation de } 4 \\
\text { à } 6 \text { du nombre } \\
\text { de selles par jour } \\
\text { par rapport à l'état } \\
\text { initial ; augmentation } \\
\text { modérée des volumes } \\
\text { de stomie par rapport } \\
\text { à l'état initial }\end{array}$ & $\begin{array}{l}\text { Augmentation de } 7 \text { ou } \\
\text { plus du nombre } \\
\text { de selles par jour } \\
\text { par rapport à l'état } \\
\text { initial ; incontinence ; } \\
\text { hospitalisation } \\
\text { requise ; } \\
\text { augmentation sévère } \\
\text { des volumes de stomie } \\
\text { par rapport à l'état } \\
\text { initial ; interférant } \\
\text { avec les activités } \\
\text { élémentaires de la vie } \\
\text { quotidienne }\end{array}$ & $\begin{array}{l}\text { Mise en jeu } \\
\text { du pronostic vital ; } \\
\text { nécessitant une prise } \\
\text { en charge en urgence }\end{array}$ & Décès \\
\hline Défaillance hépatique & - & - & $\begin{array}{l}\text { Astérixis ; } \\
\text { encéphalopathie } \\
\text { légère ; interférant } \\
\text { avec les activités } \\
\text { élémentaires de la vie } \\
\text { quotidienne }\end{array}$ & $\begin{array}{l}\text { Encéphalopathie } \\
\text { modérée à sévère ; } \\
\text { coma ; mise en jeu } \\
\text { du pronostic vital }\end{array}$ & Décès \\
\hline Dermatite bulleuse & $\begin{array}{l}\text { Asymptomatique ; } \\
\text { bulles } \\
\text { couvrant }<10 \% \\
\text { de la surface } \\
\text { corporelle }\end{array}$ & $\begin{array}{l}\text { Bulles couvrant } 10- \\
30 \% \text { de la surface } \\
\text { corporelle ; bulles } \\
\text { douloureuses ; } \\
\text { interférant } \\
\text { avec les activités } \\
\text { instrumentales } \\
\text { de la vie quotidienne }\end{array}$ & $\begin{array}{l}\text { Bulles } \\
\text { couvrant }>30 \% \\
\text { de la surface } \\
\text { corporelle ; interférant } \\
\text { avec les activités } \\
\text { élémentaires de la vie } \\
\text { quotidienne }\end{array}$ & $\begin{array}{l}\text { Bulles } \\
\text { couvrant }>30 \% \\
\text { de la surface } \\
\text { corporelle ; associées } \\
\text { à une déshydratation } \\
\text { ou des anomalies } \\
\text { électrolytiques ; } \\
\text { nécessitant } \\
\text { une surveillance } \\
\text { dans un service } \\
\text { de soins intensifs } \\
\text { ou de grands brûlé } \\
\end{array}$ & Décès \\
\hline $\begin{array}{l}\text { Éruption } \\
\text { maculopapuleuse }\end{array}$ & $\begin{array}{l}\text { Macules/papules } \\
\text { couvrant }<10 \% \\
\text { de la surface } \\
\text { corporelle } \\
\text { avec ou sans } \\
\text { symptômes associés }\end{array}$ & $\begin{array}{l}\text { Macules/papules } \\
\text { couvrant } 10-30 \% \\
\text { de la surface } \\
\text { corporelle } \\
\text { avec ou sans } \\
\text { symptômes associés }\end{array}$ & $\begin{array}{l}\text { Macules/papules } \\
\text { couvrant }>30 \% \\
\text { de la surface } \\
\text { corporelle } \\
\text { avec symptômes } \\
\text { associés ; interférant }\end{array}$ & - & - \\
\hline
\end{tabular}




\begin{tabular}{|c|c|c|c|c|c|}
\hline Type de toxicité & Grade 1 & Grade 2 & Grade 3 & Grade 4 & Grade 5 \\
\hline & $\begin{array}{l}\text { (ex. : prurit, brûlures, } \\
\text { raideur) }\end{array}$ & $\begin{array}{l}\text { (ex. : prurit, brûlures, } \\
\text { raideur) ; interférant } \\
\text { avec les activités } \\
\text { instrumentales } \\
\text { de la vie quotidienne ; } \\
\text { éruption couvrant plus } \\
\text { de } 30 \% \text { de la surface } \\
\text { corporelle } \\
\text { avec un sans } \\
\text { symptômes minimes }\end{array}$ & $\begin{array}{l}\text { avec les activités } \\
\text { élémentaires de la vie } \\
\text { quotidienne }\end{array}$ & & \\
\hline Hypothyroïdie & $\begin{array}{l}\text { Asymptomatique } \\
\text { diagnostic clinique } \\
\text { ou biologique ; } \\
\text { ne nécessitant aucun } \\
\text { traitement }\end{array}$ & $\begin{array}{l}\text { Symptomatique ; } \\
\text { nécessitant } \\
\text { un traitement } \\
\text { hormonal thyroïdien } \\
\text { de substitution ; } \\
\text { interférant } \\
\text { avec les activités } \\
\text { instrumentales } \\
\text { de la vie quotidienne }\end{array}$ & $\begin{array}{l}\text { Symptômes sévères ; } \\
\text { interférant } \\
\text { avec les activités } \\
\text { élémentaires de la vie } \\
\text { quotidienne ; } \\
\text { nécessitant } \\
\text { une hospitalisation }\end{array}$ & $\begin{array}{l}\text { Mise en jeu } \\
\text { du pronostic vital ; } \\
\text { nécessitant une prise } \\
\text { en charge en urgence }\end{array}$ & - \\
\hline Hyperthyroïdie & $\begin{array}{l}\text { Asymptomatique } \\
\text { diagnostic clinique } \\
\text { ou biologique ; } \\
\text { ne nécessitant aucun } \\
\text { traitement }\end{array}$ & $\begin{array}{l}\text { Symptomatique ; } \\
\text { indication } \\
\text { de traitement } \\
\text { suppressif } \\
\text { de la fonction } \\
\text { thyroïdienne; } \\
\text { interférant } \\
\text { avec les activités } \\
\text { instrumentales } \\
\text { de la vie quotidienne }\end{array}$ & $\begin{array}{l}\text { Symptômes sévères; } \\
\text { interférant } \\
\text { avec les activités } \\
\text { élémentaires de la vie } \\
\text { quotidienne ; } \\
\text { nécessitant } \\
\text { une hospitalisation }\end{array}$ & $\begin{array}{l}\text { Mise en jeu } \\
\text { du pronostic vital ; } \\
\text { nécessitant une prise } \\
\text { en charge en urgence }\end{array}$ & Décès \\
\hline Myocardite & $\begin{array}{l}\text { Asymptomatique } \\
\text { avec des anomalies } \\
\text { biologiques } \\
\text { ou à l'imagerie }\end{array}$ & $\begin{array}{l}\text { Symptômes lors d'une } \\
\text { activité ou d'un effort } \\
\text { légers ou modérés }\end{array}$ & $\begin{array}{l}\text { Symptômes au repos } \\
\text { ou lors d'une activité } \\
\text { ou d'un effort } \\
\text { minimes } \\
\text { avec intervention } \\
\text { indiquée }\end{array}$ & $\begin{array}{l}\text { Mise en jeu } \\
\text { du pronostic vital } \\
\text { avec nécessité d'une } \\
\text { intervention urgente } \\
\text { de type support } \\
\text { hémodynamique } \\
\text { ou traitement } \\
\text { intraveineux continu }\end{array}$ & Décès \\
\hline Pneumopathie & $\begin{array}{l}\text { Asymptomatique ; } \\
\text { diagnostic clinique } \\
\text { ou à l'imagerie ; } \\
\text { ne nécessitant aucun } \\
\text { traitement }\end{array}$ & $\begin{array}{l}\text { Symptomatique ; } \\
\text { nécessitant } \\
\text { un traitement ; } \\
\text { limitant les activités } \\
\text { instrumentales } \\
\text { de la vie quotidienne }\end{array}$ & $\begin{array}{l}\text { Symptômes sévères ; } \\
\text { interférant } \\
\text { avec les activités } \\
\text { élémentaires de la vie } \\
\text { quotidienne; } \\
\text { oxygénothérapie } \\
\text { requise }\end{array}$ & $\begin{array}{l}\text { Atteinte respiratoire } \\
\text { mettant en jeu } \\
\text { du pronostic vital ; } \\
\text { nécessitant une prise } \\
\text { en charge en urgence } \\
\text { (ex. : trachéotomie } \\
\text { ou intubation) }\end{array}$ & Décès \\
\hline
\end{tabular}

l'introduction d'un autre traitement immunosuppresseur tel que l'infliximab (anti-TNF), le cyclophosphamide ou le mycophénolate mofétil [39]. En pratique, cette décision doit être prise au cours d'une réunion de concertation pluridisci- plinaire et en prenant en compte le risque infectieux important. En effet, dans la série de Naidoo et al., sur les cinq patients traités par anti-TNF, trois sont décédés de complications infectieuses [33]. La difficulté est donc de traiter la 
pneumopathie sans induire d'immunosuppression excessive. Une toxicité pulmonaire réversible ne contre-indique pas la réintroduction du médicament, et cela doit être discuté avec l'ensemble des intervenants et le patient. Enfin, il semblerait que la toxicité pulmonaire soit associée à la réponse à l'immunothérapie, mais cela reste encore à démontrer de manière certaine [33].

Les pneumopathies immuno-induites sont donc des toxicités relativement fréquentes, potentiellement graves, voire mortelles, pour laquelle il existe plusieurs traitements dont l'indication doit être décidée lors d'une concertation pluridisciplinaire.

\section{Digestive}

Avant toute chose, il faut bien noter que dans plus de la moitié des cas, les symptômes digestifs sous immunothérapie ne sont pas liés au traitement, mais à un autre diagnostic (progression tumorale dans la majorité des cas) [42]. Il faut ainsi évoquer et explorer les autres étiologies avant d'incriminer l'immunothérapie. La diarrhée est le principal symptôme digestif sous immunothérapie ( $30 \%$ des cas tous grades confondus) et est plus fréquente avec les anti-CTLA-4 qu'avec les anti-PD-1/PD-L1, avec des toxicités de grades 3 et 4 (Tableau 2 ) dans respectivement $5 \%$ et 1 à $3 \%$ des cas [32]. La colite est plus rare, mais peut dans les cas sévères nécessiter jusqu'à la colectomie partielle en cas de nonréponse aux thérapies immunosuppressives pour saignement, perforation ou diarrhée non contrôlée. Elle apparaît en général 8 à 12 semaines après l'initiation du traitement.

Le diagnostic de certitude de colite immuno-induite repose sur la coloscopie qui peut retrouver à l'examen macroscopique un érythème de la muqueuse et parfois des ulcérations et en microscopie (biopsie nécessaire pour confirmer ou infirmer le diagnostic de colite) un infiltrat lymphocytaire (principalement TH1) et neutrophilique, des cryptes, des granulomes, des destructions glandulaires et/ou des érosions de la muqueuse [43]. L'atteinte n'est pas limitée au côlon et peut donner des ulcérations œsophagiennes, une gastrite, une atteinte iléale ou duodénale dans certains cas. Avant toute chose, il convient d'éliminer une étiologie infectieuse, en particulier une colite à Clostridium difficile ou une réactivation de CMV.

Le traitement repose sur l'arrêt de l'immunothérapie à partir du grade 2 (Tableau 2), les antidiarrhéiques, la corticothérapie initialement intraveineuse avec relais per os au bout de trois-cinq jours (pour une durée de 8 à 12 semaines). En cas d'inefficacité à trois jours, les anti-TNF comme l'infliximab peuvent être discutés, ceux-ci ayant fait la preuve de leur efficacité dans plusieurs études [31], une fois l'exploration endoscopique réalisée. En général, une seule dose d'infliximab $(5 \mathrm{mg} / \mathrm{kg})$ est suffisante, mais certains patients nécessitent une seconde dose à 15 jours d'intervalle.

\section{Hépatique}

Cette toxicité consiste le plus souvent en une élévation asymptomatique des transaminases (augmentation de la bilirubine plus rare) jusqu'à $10 \%$ des cas pour les anti-CTLA-4 contre $5 \%$ pour les anti-PD-1/PD-L1, mais plus fréquente en cas d'association avec de la chimiothérapie ou des inhibiteurs de tyrosine-kinase, et apparaît en général entre 8 à 12 semaines après initiation du traitement.

L'imagerie, qui est utile pour éliminer une étiologie maligne en particulier métastatique ou une cause lithiasique, est non spécifique, avec une hépatomégalie, un œdème périportal ou des adénopathies périportales et peut être normale dans les formes modérées. Il est indispensable d'éliminer une autre cause d'hépatite, en particulier les causes virales, les médicaments hépatotoxiques ou l'alcool. Les caractéristiques anatomopathologiques de l'hépatite immuno-induite sont une hépatite panlobulaire, un infiltrat lymphocytaire périveineux ou entourant les canaux biliaires.

L'immunothérapie doit être arrêtée à partir du grade 2 (Tableau 2), et une corticothérapie orale pour le grade 2 $(1 \mathrm{mg} / \mathrm{kg}$ ) et intraveineuse pour les grades supérieurs (1$2 \mathrm{mg} / \mathrm{kg}$ ) doit être initiée, pour une durée totale de minimum trois semaines. En cas de non-réponse aux corticoïdes après trois jours, on envisagera l'introduction de mycophénolate mofétil $(1000 \mathrm{mg} \times 2 / \mathrm{j})$, l'infliximab étant à éviter étant donné sa potentielle hépatotoxicité. Un bilan biologique tous les trois jours au stade 2 et journalier à partir du stade 3 (Tableau 2) doit être réalisé. La biopsie doit être discutée en cas de toxicité de grade 4 (Tableau 2) ou de forme réfractaire aux corticoïdes et au MMF. La prise en charge de ce type d'atteinte doit dans tous les cas être discutée lors d'une concertation multidisciplinaire.

\section{Endocrinienne}

Elles sont représentées par les hypophysites, les hyperthyroïdies, les thyroïdites, les insuffisances surrénales. Un diabète immuno-induit est extrêmement rare $(<1 \%)$, rarement grave et ne présente aucune spécificité de prise en charge.

\section{Hypophysites}

Plus fréquente avec les anti-CTLA-4 (plus de $10 \%$ des cas [44] contre 1 à $6 \%$ pour les anti-PD-1/PD-L1 en monothérapie [32]), et apparaissant en général après deux-trois mois, le diagnostic se fait sur une insuffisance de l'ensemble des axes contrôlés par l'hypophyse : diminution de la prolactine, de TSH (la première à diminuer avant le diagnostic d'hypopituitarisme)/T4, FSH/LH, ACTH/cortisol ; l'axe d'hormones de croissance est en général épargné.

Les symptômes sont non spécifiques : céphalées, troubles visuels (rares, car le degré d'élargissement pituitaire est 
généralement faible), fatigue, faiblesse musculaire, pâleur, constipation, perte de poids, anorexie, nausées, diabète insipide exceptionnel (un cas décrit). L'IRM cérébrale avec injection de gadolinium peut mettre en évidence des images d'infiltration de l'hypophyse ou d'épaississement de la tige pituitaire mais peut aussi être normale; la comparaison à une IRM antérieure peut être informative. Elle est indispensable, car elle permet par ailleurs de faire la distinction avec les principaux diagnostics différentiels qui dans ce contexte sont une atteinte métastatique cérébrale, une méningite carcinomateuse et une atteinte cérébrale vasculaire.

Le traitement consiste en supplémentation en glucocorticoïdes, en hormones thyroïdiennes et en sodium de manière précoce après arrêt de l'immunothérapie, mais peut dans de rares cas donner une insuffisance surrénale aiguë nécessitant une hospitalisation pour corticothérapie et équilibration hydroélectrolytique (à ne pas confondre avec une insuffisance surrénale périphérique, avec dans ce cas un taux d'ACTH élevé). L'hypophysite est réversible dans la plupart des cas (la forme chronique est exceptionnelle) et ne contreindique pas la reprise du traitement en cas d'atteinte non grave. De manière intéressante, la survenue d'une hypophysite est corrélée à une augmentation de la survie [45], et le traitement temporaire par glucocorticoïdes ne diminue pas l'efficacité de l'immunothérapie [44].

\section{Dysfonction thyroïdienne}

Elle peut être intermittente ou permanente et se traite comme une dysfonction thyroïdienne d'autres causes, l'hypothyroïdie étant plus fréquente que l'hyperthyroïdie. En cas de thyroïdite, une période d'hyperthyroïdie temporaire précède une hypothyroïdie permanente.

La fréquence varie de 1 à $5 \%$ avec l'ipilimumab et de 5 à $10 \%$ avec les anti-PD-1/PD-L1; elle peut aller jusqu'à $20 \%$ en cas d'association anti-PD-1 et anti-PD-L1 $[39,46]$. Le mécanisme est celui des thyroïdites auto-immunes [39].

Dans la plupart des cas, il n'est pas nécessaire de discontinuer l'immunothérapie, et aucun cas grave n'a été rapporté [31,32]. Elle nécessite une opothérapie substitutive définitive le plus souvent. La prise en charge des thyrotoxicoses ou à l'inverse des hypothyroïdies est celle habituelle, la corticothérapie est inutile.

\section{Cutanée}

Si une éruption maculopapuleuse généralisée minime à modérée et sans gravité est retrouvée dans plus d'un tiers des cas sous traitement par anti-CTLA-4 ou antiPD-1/PD-L1, les anti-CTLA, et plus rarement les antiPD-1/PD-L1, peuvent rarement donner des atteintes cutanées de grade 4 de type syndrome de Stevens-Johnson, de nécrolyse épidermique toxique (NET) ou de syndrome
DRESS (en anglais Drug Reaction with Eosinophilia and Systemic Symptoms ou syndrome d'hypersensibilité médicamenteuse) [47] qui peuvent engager le pronostic vital.

L'arrêt de l'immunothérapie est alors indispensable avec surveillance dermatologique quotidienne, et le traitement repose en priorité sur la corticothérapie systémique intraveineuse $1-2 \mathrm{mg} / \mathrm{kg}$ et le support hydroélectrolytique.

Une autre atteinte cutanée potentiellement grave plus spécifique de ce type de traitement est la pemphigoïde bulleuse. Il n'a pas encore été rapporté de pemphigoïde bulleuse avec des anti-CTLA-4 ; cela semble être donc plutôt un effet de classe des anti-PD-1/PD-L1.

L'évolution classique se fait d'abord par un prurit puis l'apparition de bulles tendues localisées ou généralisées contenant un liquide séreux ou hémorragique, avec dans 10 à $30 \%$ des cas une atteinte de la muqueuse buccale. Son diagnostic est avant tout anatomopathologique ; la biopsie doit être faite de manière rapide, avec en particulier les dépôts linéaires de $\mathrm{C} 3$ et $\mathrm{IgG}$ sur la membrane basale de la jonction dermoépidermique en immunofluorescence directe, sur le marquage en IHC des anticorps B180 et BP230 ainsi que par technique Elisa des mêmes anticorps circulants.

Le traitement repose avant tout sur l'arrêt du médicament ainsi que sur les corticoïdes en topiques qui ont montré leur supériorité sur les corticoïdes systémiques [48]. La particularité de la pemphigoïde bulleuse liée aux anti-PD-1/PD-L1 par rapport aux autres pemphigoïdes bulleuses liées aux médicaments (plus de 50 responsables) est qu'elle peut persister plusieurs mois après l'arrêt du médicament, cela étant probablement dû à la persistance de la réactivation immunitaire après arrêt de l'anticorps ; cela étant corroboré par le fait que l'ensemble des cas rapportés dans la littérature étaient associés à une réponse antitumorale prolongée [49].

\section{Cardiaque}

Les myocardites immuno-induites sont des événements extrêmement rares, se produisant sans moins de $1 \%$ des cas $[50,51]$. Elles surviennent généralement tôt après introduction de l'immunothérapie, après la deuxième injection d'anti-PD-1/PD-L1 ou d'anti-CTLA-4 [50].

Par contre, elles sont très souvent graves avec dans la moitié des cas une atteinte de grade 4 ou 5 (Tableau 2), ce qui les différencie des autres atteintes immuno-induites (pulmonaire, digestive, etc.) qui sont rarement graves, et même des myocardites non immuno-induites qui sont des myocardites fulminantes dans seulement $15 \%$ des cas. Une autre particularité par rapport aux myocardites d'autres causes est la possible conservation de la FEVG, même au stade de myocardite fulminante, dans plus d'un tiers des cas, ce qui en fait un mauvais marqueur de suivi dans ce cas [50]. Par contre, la troponine est élevée dans la grande majorité des cas [50]. 
Leur prise en charge est actuellement mal codifiée, mais un traitement de type « rejet de greffe » avec utilisation de traitement visant à la destruction des lymphocytes $\mathrm{T}$ cytotoxiques autoréactifs (mycophénolate mofétil, tacrolimus, ATG) semble être le plus efficace.

\section{Toxicités rares}

Les inhibiteurs de checkpoints immunitaires provoquent rarement des toxicités oculaires (uvéites, conjonctivite...), neurologiques en particulier avec les anti-CTLA-4 ou les combinaisons (Guillain-Barré, méningite lymphocytaire, PRESS, myélite), rénales (néphropathie interstitielle, néphropathie glomérulaire ou néphropathie glomérulaire lupus-like) pouvant provoquer une insuffisance rénale aiguë, pancréatiques (anomalies des enzymes hépatiques donnant exceptionnellement une pancréatite), cardiaques (myocardites extrêmement rares, mais plus fréquemment décrites avec les combinaisons et mortelles dans plus de la moitié des cas) et cytopénies d'origine auto-immunes (anémies hémolytiques, thrombocytopénies, neutropénies auto-immunes, aplasies, hémophilies acquises). Avec l'extension des indications, du nombre de patients traités, ainsi que les combinaisons d'immunothérapies ces complications risquent d'augmenter.

\section{Particularités des combinaisons}

Si les associations ont permis d'obtenir des résultats impressionnants en termes de réponses prolongées dans le mélanome en particulier [46], cela se fait au prix d'une augmentation importante des toxicités par rapport aux monothérapies, plus de $50 \%$ de grade $3 / 4$ contre moins de $30 \%$ en monothérapie, avec en particulier un arrêt de traitement dans près de $40 \%$ des cas, et une résolution dans la majorité des cas, de 85 à $100 \%$ des cas [46,52]. L'incidence des pneumopathies par exemple est doublée en cas de combinaisons anti-PD-1/PD-L1 et anti-CTLA-4 [33,34]. Pour ce qui est des myocardites, un événement exceptionnel en cas de monothérapie $(0,06 \%$ pour le nivolumab) devient un événement rare en cas d'association $(0,27 \%$ des cas pour nivolumab et ipilimumab) selon les données fournies par BristolMyers Squibb [51], de surcroît probablement sous-évaluées.

\section{Perspectives}

L'inventaire des toxicités liées à l'immunothérapie continue à s'agrandir avec le recul sur l'introduction de ces nouvelles immunothérapies et avec l'émergence des associations d'immunothérapie ; en effet, en plus des associations antiPD-1/PD-L1 et CTLA-4 vont bientôt émerger de nouvelles immunothérapies, de nouveaux inhibiteurs de «checkpoint», des costimulateurs, des stimulateurs de transfert des lympho-

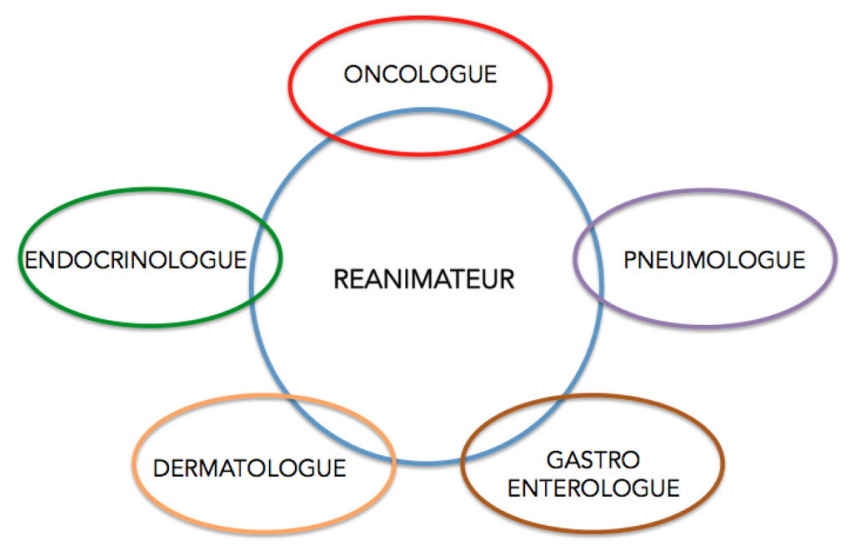

Fig. 2 Schéma de prise en charge pluridisciplinaire

cytes $\mathrm{T}$ dans la tumeur, des vaccins, des agents immunostimulateurs ou des CAR T-cells, etc. [53,54]. Il semble indispensable de développer la coopération entre les différents spécialistes d'organes (gastroentérologues, néphrologues, endocrinologues...) afin de prendre en charge au mieux ces atteintes spécifiques d'organes (Fig. 2). Les centres spécialisés ont organisé des réunions de concertation pluridisciplinaires dédiées comme par exemple le groupe Partage d'expérience autour des toxicités en immuno-oncologie (PATIO). Le binôme oncologue-réanimateur (pour les toxicités sévères) doit s'y intégrer et ainsi permettre d'améliorer la prise en charge de ces complications. La construction de prises en charge standardisées permet de mieux appréhender les toxicités de ce nouveau pilier du traitement du cancer qui devient de plus en plus incontournable. Enfin, dans la plupart des cas, la toxicité de l'immunothérapie est corrélée à l'efficacité antitumorale (phénomène rare hormis avec l'hypertension artérielle et la réponse aux anti-VEGF dans le cancer du rein, encore controversée [55] ou l'éruption cutanée et l'efficacité de l'anti-EGFR cetuximab dans le cancer du côlon [56]) et ne contre-indique pas forcément la reprise du traitement, ce qui fait envisager la prise en charge de celles-ci d'une autre manière que les toxicités liées aux chimiothérapies, notamment en termes d'engagement dans les soins.

Remerciements : les auteurs remercient Guilhem Pujol pour sa contibution à la conception des figures.

Liens d'intérêts : les auteurs déclarent ne pas avoir de lien d'intérêt.

\section{Références}

1. Hanahan D, Weinberg RA, (2000) The hallmarks of cancer. Cell 100: $57-70$

2. Hanahan D, Weinberg RA, (2011) Hallmarks of cancer: the next generation. Cell 144: 646-674 
3. Coley WB, (1991) The treatment of malignant tumors by repeated inoculations of erysipelas. With a report of ten original cases. 1893. Clin Orthop 3-11

4. Rouprêt M, Neuzillet Y, Masson-Lecomte A, Colin P, Compérat E, Dubosq F, Houédé N, Larré S, Pignot G, Puech P, Roumiguié M, Xylinas E, Méjean A, (2016) Recommandations en oncourologie 2016-2018 du CCAFU : tumeurs de la vessie. /data/ revues/11667087/v27sS1/S1166708716307047/

5. Fridman WH, (2016) Historique de l'immunothérapie. Changement de paradigme ? Bull Cancer (Paris) 103: S122-S126

6. Maude SL, Frey N, Shaw PA, Aplenc R, Barrett DM, Bunin NJ, Chew A, Gonzalez VE, Zheng Z, Lacey SF, Mahnke YD, Melenhorst JJ, Rheingold SR, Shen A, Teachey DT, Levine BL, June CH, Porter DL, Grupp SA, (2014) Chimeric antigen receptor T-cells for sustained remissions in leukemia. N Engl J Med 371: 1507

7. Kantoff PW, Higano CS, Shore ND, Berger ER, Small EJ, Penson DF, Redfern CH, Ferrari AC, Dreicer R, Sims RB, Xu Y, Frohlich MW, Schellhammer PF, (2010) Sipuleucel-T immunotherapy for castration-resistant prostate cancer. N Engl J Med 363: 411-422

8. Kroemer G, Galluzzi L, Kepp O, Zitvogel L, (2013) Immunogenic cell death in cancer therapy. Annu Rev Immunol 31: 51-72

9. Sapoznik S, Hammer O, Ortenberg R, Besser MJ, Ben-Moshe T, Schachter J, Markel G, (2012) Novel anti-melanoma immunotherapies: disarming tumor escape mechanisms. Clin Dev Immunol. doi: $10.1155 / 2012 / 818214$

10. Pardoll DM, (2012) The blockade of immune checkpoints in cancer immunotherapy. Nat Rev Cancer 12: 252-264

11. Alexandrov LB, Nik-Zainal S, Wedge DC, Aparicio SAJR, Behjati S, Biankin AV, Bignell GR, Bolli N, Borg A, Børresen-Dale AL, Boyault S, Burkhardt B, Butler AP, Caldas C, Davies HR, Desmedt C, Eils R, Eyfjörd JE, Foekens JA, Greaves M, Hosoda F, Hutter B, Ilicic T, Imbeaud S, Imielinsk M, Jäger N, Jones DTW, Jones D, Knappskog S, Kool M, Lakhani SR, LópezOtín C, Martin S, Munshi NC, Nakamura H, Northcott PA, Pajic M, Papaemmanuil E, Paradiso A, Pearson JV, Puente XS, Raine K, Ramakrishna M, Richardson AL, Richter J, Rosenstiel P, Schlesner M, Schumacher TN, Span PN, Teague JW, Totoki Y, Tutt ANJ, Valdés-Mas R, van Buuren MM, van 't Veer L, Vincent-Salomon A, Waddell N, Yates LR, Zucman-Rossi J, Futreal PA, McDermott U, Lichter P, Meyerson M, Grimmond SM, Siebert R, Campo E, Shibata T, Pfister SM, Campbell PJ, Stratton MR, (2013) Signatures of mutational processes in human cancer. Nature 500: 415-421

12. Lawrence MS, Stojanov P, Polak P, Kryukov GV, Cibulskis K, Sivachenko A, Carter SL, Stewart C, Mermel CH, Roberts SA, Kiezun A, Hammerman PS, McKenna A, Drier Y, Zou L, Ramos AH, Pugh TJ, Stransky N, Helman E, Kim J, Sougnez C, Ambrogio L, Nickerson E, Shefler E, Cortés ML, Auclair D, Saksena G, Voet D, Noble M, DiCara D, Lin P, Lichtenstein L, Heiman DI, Fennell T, Imielinski M, Hernandez B, Hodis E, Baca S, Dulak AM, Lohr J, Landau DA, Wu CJ, Melendez-Zajgla J, HidalgoMiranda A, Koren A, McCarroll SA, Mora J, Crompton B, Onofrio R, Parkin M, Winckler W, Ardlie K, Gabriel SB, Roberts CWM, Biegel JA, Stegmaier K, Bass AJ, Garraway LA, Meyerson M, Golub TR, Gordenin DA, Sunyaev S, Lander ES, Getz G, (2013) Mutational heterogeneity in cancer and the search for new cancer genes. Nature 499: 214-218

13. Le DT, Uram JN, Wang H, Bartlett BR, Kemberling H, Eyring $\mathrm{AD}$, Skora AD, Luber BS, Azad NS, Laheru D, Biedrzycki B, Donehower RC, Zaheer A, Fisher GA, Crocenzi TS, Lee JJ, Duffy SM, Goldberg RM, de la Chapelle A, Koshiji M, Bhaijee F, Huebner T, Hruban RH, Wood LD, Cuka N, Pardoll DM, Papadopoulos N, Kinzler KW, Zhou S, Cornish TC, Taube JM, Anders RA, Eshleman JR, Vogelstein B, Diaz LAJ, (2015) PD-1
Blockade in tumors with mismatch-repair deficiency. N Engl $\mathrm{J}$ Med 372: 2509-2520

14. Rizvi NA, Hellmann MD, Snyder A, Kvistborg P, Makarov V, Havel JJ, Lee W, Yuan J, Wong P, Ho TS, Miller ML, Rekhtman N, Moreira AL, Ibrahim F, Bruggeman C, Gasmi B, Zappasodi R, Maeda Y, Sander C, Garon EB, Merghoub T, Wolchok JD, Schumacher TN, Chan TA, (2015) Mutational landscape determines sensitivity to PD-1 blockade in non-small cell lung cancer. Science 348: 124-128

15. Snyder A, Makarov V, Merghoub T, Yuan J, Zaretsky JM, Desrichard A, Walsh LA, Postow MA, Wong P, Ho TS, Hollmann TJ, Bruggeman C, Kannan K, Li Y, Elipenahli C, Liu C, Harbison CT, Wang L, Ribas A, Wolchok JD, Chan TA, (2014) Genetic basis for clinical response to CTLA-4 blockade in melanoma. $\mathrm{N}$ Engl J Med 371: 2189-2199

16. Van Allen EM, Miao D, Schilling B, Shukla SA, Blank C, Zimmer L, Sucker A, Hillen U, Foppen MHG, Goldinger SM, Utikal J, Hassel JC, Weide B, Kaehler KC, Loquai C, Mohr P, Gutzmer R, Dummer R, Gabriel S, Wu CJ, Schadendorf D, Garraway LA, (2015) Genomic correlates of response to CTLA-4 blockade in metastatic melanoma. Science 350: 207-211

17. Hellmann MD, Ciuleanu TE, Pluzanski A, Lee JS, Otterson GA, Audigier-Valette C, Minenza E, Linardou H, Burgers S, Salman P, Borghaei H, Ramalingam SS, Brahmer J, Reck M, O’Byrne KJ, Geese WJ, Green G, Chang H, Szustakowski J, Bhagavatheeswaran P, Healey D, Fu Y, Nathan F, Paz-Ares L, (2018) Nivolumab plus ipilimumab in lung cancer with a high tumor mutational burden. N Engl J Med doi: 10.1056/NEJMoa1801946

18. Hellmann MD, Callahan MK, Awad MM, Calvo E, Ascierto PA, Atmaca A, Rizvi NA, Hirsch FR, Selvaggi G, Szustakowski JD, Sasson A, Golhar R, Vitazka P, Chang H, Geese WJ, Antonia SJ, (2018) Tumor mutational burden and efficacy of nivolumab monotherapy and in combination with ipilimumab in small-cell lung cancer. Cancer Cell doi: 10.1016/j.ccell.2018.04.001

19. Pagès F, Granier C, Kirilovsky A, Elsissy C, Tartour E, (2016) Biomarqueurs prédictifs de réponse aux traitements bloquant les voies de costimulation inhibitrices. Bull Cancer (Paris) 103: S151-S159

20. Fridman WH, Pagès F, Sautès-Fridman C, Galon J, (2012) The immune contexture in human tumours: impact on clinical outcome. Nat Rev Cancer 12: 298-306

21. Ji RR, Chasalow SD, Wang L, Hamid O, Schmidt H, Cogswell J, Alaparthy S, Berman D, Jure-Kunkel M, Siemers NO, Jackson JR, Shahabi V, (2012) An immune-active tumor microenvironment favors clinical response to ipilimumab. Cancer Immunol Immunother 61: 1019-1031

22. Hamid O, Schmidt H, Nissan A, Ridolfi L, Aamdal S, Hansson J, Guida M, Hyams DM, Gómez H, Bastholt L, Chasalow SD, Berman D, (2011) A prospective phase II trial exploring the association between tumor microenvironment biomarkers and clinical activity of ipilimumab in advanced melanoma. J Transl Med 9: 204

23. Diem S, Schmid S, Krapf M, Flatz L, Born D, Jochum W, Templeton AJ, Früh M, (2017) Neutrophil-to-Lymphocyte Ratio (NLR) and Platelet-to-Lymphocyte Ratio (PLR) as prognostic markers in patients with Non-Small Cell Lung Cancer (NSCLC) treated with nivolumab. Lung Cancer Amst Neth 111: 176-181

24. Blackley E, Lim LE, Moore M, Voskoboynik M, McLean C, Haydon A, (2017) 1242PNeutrophil to Lymphocyte Ratio (NLR) as an independent prognostic measure in patients receiving targeted therapy or immunotherapy for stage IV melanoma. Ann Oncol doi: 10.1093/annonc/mdx377.028

25. Mezquita L, Auclin E, Ferrara R, Charrier M, Remon J, Planchard D, Ponce S, Ares LP, Leroy L, Audigier-Valette C, Felip E, Zerón-Medina J, Garrido P, Brosseau S, Zalcman G, Mazieres J, Caramela C, Lahmar J, Adam J, Chaput N, Soria JC, Besse B, (2018) Association of the Lung Immune Prognostic Index with 
immune checkpoint inhibitor outcomes in patients with advanced Non-Small Cell Lung Cancer. JAMA Oncol 4: 351-357

26. Hodi FS, Butler M, Oble DA, Seiden MV, Haluska FG, Kruse A, MacRae S, Nelson M, Canning C, Lowy I, Korman A, Lautz D, Russell S, Jaklitsch MT, Ramaiya N, Chen TC, Neuberg D, Allison JP, Mihm MC, Dranoff G, (2008) Immunologic and clinical effects of antibody blockade of cytotoxic $\mathrm{T}$ lymphocyteassociated antigen 4 in previously vaccinated cancer patients. Proc Natl Acad Sci U S A 105: 3005-3010

27. Seymour L, Bogaerts J, Perrone A, Ford R, Schwartz LH, Mandrekar S, Lin NU, Litière S, Dancey J, Chen A, Hodi FS, Therasse P, Hoekstra OS, Shankar LK, Wolchok JD, Ballinger M, Caramella C, Vries EGE de, (2017) iRECIST: guidelines for response criteria for use in trials testing immunotherapeutics. Lancet Oncol 18: e143-e152

28. Wolchok JD, Hoos A, O'Day S, Weber JS, Hamid O, Lebbé C, Maio M, Binder M, Bohnsack O, Nichol G, Humphrey R, Hodi FS, (2009) Guidelines for the evaluation of immune therapy activity in solid tumors: immune-related response criteria. Clin Cancer Res 15: 7412-7420

29. Chiou VL, Burotto M, (2015) Pseudoprogression and immunerelated response in solid tumors. J Clin Oncol 33: 3541-3543

30. Kurra V, Sullivan RJ, Gainor JF, Hodi FS, Gandhi L, Sadow CA, Harris GJ, Flaherty K, Lee S, (2016) Pseudoprogression in cancer immunotherapy: rates, time course and patient outcomes. J Clin Oncol 34

31. Michot JM, Bigenwald C, Champiat S, Collins M, Carbonnel F, Postel-Vinay S, Berdelou A, Varga A, Bahleda R, Hollebecque A, Massard C, Fuerea A, Ribrag V, Gazzah A, Armand JP, Amellal N, Angevin E, Noel N, Boutros C, Mateus C, Robert C, Soria JC, Marabelle A, Lambotte O, (2016) Immune-related adverse events with immune checkpoint blockade: a comprehensive review. Eur J Cancer 54: 139-148

32. Naidoo J, Page DB, Li BT, Connell LC, Schindler K, Lacouture ME, Postow MA, Wolchok JD, (2015) Toxicities of the anti-PD-1 and anti-PD-L1 immune checkpoint antibodies. Ann Oncol 26: 2375-2391

33. Naidoo J, Wang X, Woo KM, Iyriboz T, Halpenny D, Cunningham J, Chaft JE, Segal NH, Callahan MK, Lesokhin AM, Rosenberg J, Voss MH, Rudin CM, Rizvi H, Hou X, Rodriguez K, Albano M, Gordon RA, Leduc C, Rekhtman N, Harris B, Menzies AM, Guminski AD, Carlino MS, Kong BY, Wolchok JD, Postow MA, Long GV, Hellmann MD, (2017) Pneumonitis in patients treated with anti-programmed death-1/programmed death ligand 1 therapy. J Clin Oncol 35: 709-717

34. Nishino M, Giobbie-Hurder A, Hatabu H, Ramaiya NH, Hodi FS, (2016) Incidence of programmed cell death 1 inhibitor-related pneumonitis in patients with advanced cancer: a systematic review and meta-analysis. JAMA Oncol 2: 1607-1616

35. Hodi FS, Lee S, McDermott DF, Rao UN, Butterfield LH, Tarhini AA, Leming P, Puzanov I, Shin D, Kirkwood JM, (2014) Ipilimumab plus sargramostim vs ipilimumab alone for treatment of metastatic melanoma: a randomized clinical trial. JAMA 312: 1744-1753

36. Tirumani SH, Ramaiya NH, Keraliya A, Bailey ND, Ott PA, Hodi FS, Nishino M, (2015) Radiographic profiling of immunerelated adverse events in advanced melanoma patients treated with ipilimumab. Cancer Immunol Res 3: 1185-1192

37. Delaunay M, Cadranel J, Lusque A, Meyer N, Gounant V, MoroSibilot D, Michot JM, Raimbourg J, Girard N, Guisier F, Planchard D, Metivier AC, Tomasini P, Dansin E, Pérol M, Campana M, Gautschi O, Früh M, Fumet JD, Audigier-Valette C, Couraud S, Dalle S, Leccia MT, Jaffro M, Collot S, Prévot G, Milia J, Mazieres J, (2017) Immune-checkpoint inhibitors associated with interstitial lung disease in cancer patients. Eur Respir J 50: 1700050
38. Nishino M, Ramaiya NH, Awad MM, Sholl LM, Maattala JA, Taibi M, Hatabu H, Ott PA, Armand PF, Hodi FS, (2016) PD-1 inhibitorrelated pneumonitis in advanced cancer patients: radiographic patterns and clinical course. Clin Cancer Res 22: 6051-6060

39. Haanen JBAG, Carbonnel F, Robert C, Kerr KM, Peters S, Larkin J, Jordan K; on behalf of the ESMO Guidelines Committee, (2017) Management of toxicities from immunotherapy: ESMO clinical practice guidelines for diagnosis, treatment and followup. Ann Oncol 28: iv119-iv142

40. Topalian SL, Hodi FS, Brahmer JR, Gettinger SN, Smith DC, McDermott DF, Powderly JD, Carvajal RD, Sosman JA, Atkins MB, Leming PD, Spigel DR, Antonia SJ, Horn L, Drake CG, Pardoll DM, Chen L, Sharfman WH, Anders RA, Taube JM, McMiller TL, Xu H, Korman AJ, Jure-Kunkel M, Agrawal S, McDonald D, Kollia GD, Gupta A, Wigginton JM, Sznol M, (2012) Safety, activity, and immune correlates of anti-PD-1 antibody in cancer. N Engl J Med 366: 2443-2454

41. Nishino M, Sholl LM, Hatabu H, Ramaiya NH, Hodi FS, (2015) Anti-PD-1-related pneumonitis during cancer immunotherapy. N Engl J Med 373: 288-290

42. Collins M, Michot JM, Danlos FX, Mussini C, Soularue E, Mateus C, Loirat D, Buisson A, Rosa I, Lambotte O, Laghouati S, Chaput N, Coutzac C, Voisin AL, Soria JC, Marabelle A, Champiat S, Robert C, Carbonnel F, (2017) Inflammatory gastrointestinal diseases associated with PD-1 blockade antibodies. Ann Oncol 28: 2860-2865

43. Cramer P, Bresalier RS, (2017) Gastrointestinal and hepatic complications of immune checkpoint inhibitors. Curr Gastroenterol Rep 19: 3

44. Faje A, (2016) Immunotherapy and hypophysitis: clinical presentation, treatment, and biologic insights. Pituitary 19: 82-92

45. Faje AT, Sullivan R, Lawrence D, Tritos NA, Fadden R, Klibanski A, Nachtigall L, (2014) Ipilimumab-induced hypophysitis: a detailed longitudinal analysis in a large cohort of patients with metastatic melanoma. J Clin Endocrinol Metab 99: 4078-4085

46. Larkin J, Chiarion-Sileni V, Gonzalez R, Grob JJ, Cowey CL, Lao CD, Schadendorf D, Dummer R, Smylie M, Rutkowski P, Ferrucci PF, Hill A, Wagstaff J, Carlino MS, Haanen JB, Maio M, Marquez-Rodas I, McArthur GA, Ascierto PA, Long GV, Callahan MK, Postow MA, Grossmann K, Sznol M, Dreno B, Bastholt L, Yang A, Rollin LM, Horak C, Hodi FS, Wolchok JD, (2015) Combined nivolumab and ipilimumab or monotherapy in untreated melanoma. N Engl J Med 373: 23-34

47. Postow MA, (2015) Managing immune checkpoint-blocking antibody side effects. Am Soc Clin Oncol Educ Book Am Soc Clin Oncol Meet 76-83

48. Joly P, Roujeau JC, Benichou J, Picard C, Dreno B, Delaporte E, Vaillant L, D'Incan M, Plantin P, Bedane C, Young P, Bernard P, (2002) A comparison of oral and topical corticosteroids in patients with bullous pemphigoid. N Engl J Med 346: 321-327

49. Naidoo J, Schindler K, Querfeld C, Busam K, Cunningham J, Page DB, Postow MA, Weinstein A, Lucas AS, Ciccolini KT, Quigley EA, Lesokhin AM, Paik PK, Chaft JE, Segal NH, D'Angelo SP, Dickson MA, Wolchok JD, Lacouture ME, (2016) Autoimmune bullous skin disorders with immune checkpoint inhibitors targeting PD-1 and PD-L1. Cancer Immunol Res 4: 383-389

50. Mahmood SS, Fradley MG, Cohen JV, Nohria A, Reynolds KL, Heinzerling LM, Sullivan RJ, Damrongwatanasuk R, Chen CL, Gupta D, Kirchberger MC, Awadalla M, Hassan MZO, Moslehi JJ, Shah SP, Ganatra S, Thavendiranathan P, Lawrence DP, Groarke JD, Neilan TG, (2018) Myocarditis in patients treated with immune checkpoint inhibitors. J Am Coll Cardiol 71: 1755-1764

51. Johnson DB, Balko JM, Compton ML, Chalkias S, Gorham J, Xu Y, Hicks M, Puzanov I, Alexander MR, Bloomer TL, Becker JR, Slosky DA, Phillips EJ, Pilkinton MA, Craig-Owens L, Kola N, Plautz G, Reshef DS, Deutsch JS, Deering RP, Olenchock BA, 
Lichtman AH, Roden DM, Seidman CE, Koralnik IJ, Seidman JG, Hoffman RD, Taube JM, Diaz LAJ, Anders RA, Sosman JA, Moslehi JJ, (2016) Fulminant myocarditis with combination immune checkpoint blockade. N Engl J Med 375: 1749-1755

52. Postow MA, Chesney J, Pavlick AC, Robert C, Grossmann K, McDermott D, Linette GP, Meyer N, Giguere JK, Agarwala SS, Shaheen M, Ernstoff MS, Minor D, Salama AK, Taylor M, Ott PA, Rollin LM, Horak C, Gagnier P, Wolchok JD, Hodi FS, (2015) Nivolumab and ipilimumab versus ipilimumab in untreated melanoma. N Engl J Med 372: 2006-2017

53. Kroemer G, Senovilla L, Galluzzi L, André F, Zitvogel L, (2015) Natural and therapy-induced immunosurveillance in breast cancer. Nat Med 21: 1128-1138
54. Chen DS, Mellman I, (2013) Oncology meets immunology: the cancer-immunity cycle. Immunity 39: 1-10

55. Gordon MS, Margolin K, Talpaz M, Sledge GW, Holmgren E, Benjamin R, Stalter S, Shak S, Adelman D, (2001) Phase I safety and pharmacokinetic study of recombinant human anti-vascular endothelial growth factor in patients with advanced cancer. J Clin Oncol 19: 843-850

56. Cunningham D, Humblet Y, Siena S, Khayat D, Bleiberg H, Santoro A, Bets D, Mueser M, Harstrick A, Verslype C, Chau I, Van Cutsem E, (2004) Cetuximab monotherapy and cetuximab plus irinotecan in irinotecan-refractory metastatic colorectal cancer. N Engl J Med 351: 337-345 